\section{Effects of the physiochemical culture environment on the stemness and pluripotency of human embryonic stem cells}

\author{
Kristiina Rajala,' Hanna Vaajasaari,' \\ Riitta Suuronen, ${ }^{1,2,3}$ Outi Hovatta, ${ }^{4}$ \\ Heli Skottman \\ ${ }^{1}$ Regea, Institute for Regenerative \\ Medicine, Tampere University Hospital, \\ Finland; \\ 2Department of Biomedical Engineering, \\ University of Technology, Tampere, \\ Finland; \\ ${ }^{3}$ Department of Eye, Ear and Oral \\ Diseases, Tampere University Hospital, \\ Finland; \\ ${ }^{4}$ Department of Clinical Science, \\ Intervention and Technology, Karolinska \\ Institutet, Stockholm, Sweden
}

\section{Abstract}

Both physical and chemical signals in the culture environment mediate stem cell fate. For research and the clinical application of stem cells, the development of defined and xeno-free culture conditions to maintain the undifferentiated growth of human embryonic stem cells (hESCs) is highly desirable. We evaluated the effects of different basal media, glucose concentrations, osmolarity, chemical compounds, and hypoxic conditions on hESC self-renewal using defined and xeno-free culture conditions and molecular characterization of the cultured hESCs. Our findings indicate that a combination of KnockOut ${ }^{\mathrm{TM}}$ DMEM basal medium, high glucose concentration, and osmolarity of 320-330 m0sm was optimal for maintaining the self-renewal of hESCs under defined, xeno-free conditions. In addition, specific lipids, retinol, and insulin further enhanced the growth of undifferentiated hESCs. Finally, hypoxic conditions increased proliferation and prevented the spontaneous differentiation of hESCs. Although the transcriptional expression of common genes associated with pluripotency was not affected by hypoxia, the translational expression of 0ct4 increased significantly under hypoxic conditions. Our results indicated that hypoxiainduced regulation of cell signaling also involves the activation of the calcium and protein kinase $\mathrm{C}$ pathway, and several hypoxia signaling-related genes. We identified important nutrients and growth factors required for a defined, xeno-free culture condition to enable reasonable growth characteristics and to maintain the self-renewal of hESCs.
Furthermore, we demonstrated that hypoxia supports hESC self-renewal in culture. The use of defined conditions for culturing hESCs will allow for better understanding of pluripotent stem cell regulation and provide more reproducible results.

\section{Introduction}

Since the first human embryonic stem cell (hESC) line was established, ${ }^{1}$ various conditions for their derivation and culture have been described. Human ESC culture conditions have recently progressed from cultures on mouse embryonic fibroblasts (MEFs) in fetal bovine serum (FBS)-containing medium toward more defined culture systems. ${ }^{2}$ In addition to the use of human feeder cells and KnockOut $^{\mathrm{TM}}$ serum replacement (KO-SR, Invitrogen Corp., San Diego, CA, USA), ${ }^{3,4}$ several feeder-cell independent conditions for hESC culture have been described. ${ }^{5-7}$ Despite this progress, most existing hESC lines have been exposed to undefined xenogeneic products during in vitro culture. The potential consequences of transplanting human cells exposed to xeno-products into patients include an increased risk for immunoreactions, viral or bacterial infections, prions, and yet-unidentified animal pathogens. ${ }^{8-10}$ Therefore, for clinical application, it is essential to develop chemically-defined and xeno-free conditions for pluripotent stem cell derivation and expansion.

To develop chemically-defined culture environment that maintains hESC self-renewal properties, it is important to determine the signals and mechanisms that control the potential cell fates. Over the last few years, a number of molecular factors have been identified as important regulators of hESC self-renewal. Among these, transforming growth factor (TGF) $-\beta$ superfamily members, namely TGF- $\beta$, Activin A, and Nodal, play a major role in stem cell self-renewal by inducing phosphorylation of the intracellular mediators Smad2 and/or Smad3.7,11,12 In addition, Activin A induces the expression of several pluripotency genes, such as 0ct4 and Nanog, and stimulatory growth factors, such as Nodal, Wnt3, basic fibroblast growth factor (bFGF), and FGF-8. ${ }^{13}$ Another important regulator of hESC self-renewal is bFGF, which seems to act in part by inducing the expression of TGF- $\beta$ family molecules. ${ }^{14}$ More complex is the role of the Wnt family of proteins, for which there are controversial reports concerning their role in hESC selfrenewal. ${ }^{15,16}$ Inhibition of bone morphogenic protein (BMP) activity may also enhance the maintenance of hESCs in a pluripotent state. ${ }^{14,17}$ Insulin-like growth factor (IGF)-II is a critical regulator of hESC self-renewal being
Correspondence: Kristiina Rajala, Regea Institute for Regenerative Medicine, Tampere University Hospital, FI-33520 Tampere, Finland. Tel. +358.401.901.791 - Fax: +358.335.518.498 E-mail: kristiina.m.rajala@regea.fi;

Key words: human embryonic stem cell, culture conditions, hypoxia, stem cell regulation.

Acknowledgement: we thank Heini Huhtala for the statistical analyses, and Hanna Koskenaho, Niina Ikonen, Sari Leinonen, and Outi Melin for technical assistance with the hESCs. This work was supported by grants from the Academy of Finland (Grant 212776); TEKES the Finnish Funding Agency for Technology and Innovation (Grant 1128/31/05 and 3524/31/07); the Competitive Research Funding of the Pirkanmaa Hospital District (Grant 9H197), and the Swedish Research Council (grant number K2007-54X15080-04-3).

Contributions: KR and HS conceived and designed the study; KR and HV performed the experiments and analysed the data; $\mathrm{OH}$ contributed materials; KR, HV, RS, OH, HS interpreted the results and wrote the paper.

Conflict of interests: the authors Kristiina Rajala, Riitta Suuronen, Outi Hovatta, and Heli Skottman declare competing financial interests defined as patent application, Formulation and methods for culturing embryonic stem cells, Patent application/FI2009/20096288, relating to the xeno-free culture medium described in the article.

Received for publication: 30 November 2010

Revision received: 19 January 2011.

Accepted for publication: 19 January 2011.

This work is licensed under a Creative Commons Attribution 3.0 License (by-nc 3.0).

(C) Copyright K. Rajala, et al., 2011

Licensee PAGEPress, Italy

Stem Cell Studies 2011; 1:e3

doi:10.4081/scs.2011.e3

expressed in response to bFGF in parallel with TGF $/$ /Nodal/Activin. ${ }^{18}$ Another study described the importance of IGF-I signaling for hESC self-renewal, as well as a role for heregulin-1 $\beta$, an ErbB2/3 ligand, and Activin A. ${ }^{19}$ Rho-associated kinase inhibitor, neurotrophins, and pleiotrophin also act to regulate hESC survival by inhibiting apoptosis. ${ }^{20-22}$

In addition to growth factor proteins, lipid molecules, abundant in serum, are important factors in maintaining hESC self-renewal. Sphingosine-1-phosphate (S1P) and plateletderived growth factor (PDGF) synergistically stimulate the self-renewal of hESCs grown on MEFs but S1P or PDGF alone have no significant effect. ${ }^{23,24}$ Another report has described a significant role for S1P alone in the promotion of hESC survival, by reducing apoptosis and 
increasing proliferation. ${ }^{25}$ Albumin-associated lipids present in KO-SR also have a strong effect on hESC self-renewal. ${ }^{26}$ The major lipids bound to the lipid-rich albumin have been identified and several lipid candidates: lysophosphatidylcholine, lysophosphatidic acid, S1P, prostaglandin (PG) E2, and dexamethasone have been tested in hESC culture, but the active lipid responsible for the positive effect of AlbuMAX (Invitrogen Corp.) on hESC self-renewal is not yet known. Lysophosphatidic acid inhibits neuronal differentiation of hESCs by activating the Rho/Rho-associated kinase and P13/Akt pathways ${ }^{27}$ and PGE2 inhibits apoptosis of mouse ESCs (mESCs) via the P13K and Akt pathways. ${ }^{28}$ Furthermore, retinol, the alcohol form of vitamin A, supports the self-renewal of mESCs by inducing the over-expression of Nanog, a key transcription factor for self-renewal. ${ }^{29,30}$

Oxygen is a potent signaling molecule that has received increasing recognition for its ability to affect the fundamental characteristics of various stem cell types. ${ }^{31}$ Hypoxia promotes the proliferation of mESCs through the arachidonic acid and P13K/Akt signaling pathways and increases differentiation via suppression of the LIF-STAT3 signaling pathway. ${ }^{32,33}$ Reports describing the effects of hypoxia on hESC self-renewal, however, have been controversial in terms of proliferation and the prevention of spontaneous differentiation. $^{34-38}$ The variability of the observed responses may be due to differences in hESC lines and culture conditions, including various degrees of hypoxia, exposure to normoxia during manipulation of the cells, culture media, feeder cells, and passaging methods. Hypoxia was recently reported to improve the efficiency of pluripotent stem cell generation from mouse and human somatic cells. ${ }^{39}$ The Notch signaling pathway has been suggested to be involved in maintaining hESC self-renewal under hypoxic conditions..$^{36}$ Oct4, an essential transcription factor for self-renewal, is an HIF-2 $\alpha$ specific target gene. ${ }^{31}$ Microarray analysis recently performed on hESC lines cultured under hypoxic and normoxic conditions revealed 149 differentially expressed genes. ${ }^{37}$ Although genes associated with pluripotency, including Oct4, Sox2, and Nanog, were mainly unaffected, the expression of some genes controlled by these transcription factors, including LEFTY, was increased under hypoxia. ${ }^{37} \mathrm{~A}$ comprehensive characterization of the molecular mechanisms directly affecting hESCs and favoring pluripotency under hypoxia has yet to be described.

We previously described the development of a defined, xeno-free culture medium (RegES) capable of supporting the derivation of hESC lines and expansion of hESCs, induced pluripotent stem cells and adipose-derived stem cells while maintaining the characteris- tics including differentiation potential. ${ }^{40,41}$ Here, we investigated the effects of different basal media, glucose concentrations, osmolarity, and molecular factors on hESC self-renewal to optimize the defined, xeno-free conditions. We also evaluated whether hypoxia has beneficial effects on the culture of undifferentiated hESCs, especially in defined, xeno-free culture conditions, and to gain insight into the possible molecular mechanisms through which self-renewal is maintained under hypoxic conditions.

\section{Materials and Methods}

\section{Cell Culture}

The hESC lines HS346 and HS401 were initially derived and characterized at the Karolinska Institutet, Stockholm, Sweden ${ }^{42,43}$ with the permission of the Ethics Committee of the Karolinska Institutet. All the other cell lines (Regea, 06/015, 06/040, 07/046, 08/013, and $08 / 017$ ) used in the study were derived and characterized at the Institute for Regenerative Medicine, Tampere, Finland, with the approval of the Ethics Committee of Pirkanmaa Hospital District. Cell lines were derived and cultured using either the conventional hES medium containing KO-Dulbecco's Modified Eagle's Medium (DMEM, Sigma Aldrich, St. Louis, MO, USA) basal medium supplemented with $20 \%$ K0-SR, 2 mM Glutamax, $0.1 \mathrm{mM} \beta$-mercaptoethanol (all from Invitrogen Corp.), $0.1 \mathrm{mM}$ MEM non-essential amino acids, $1 \%$ penicillinstreptomycin (both from Cambrex Bio Science Corp., East Rutherford, NJ, USA), and 8 ng/mL recombinant human bFGF (R\&D Systems, Minneapolis, MN, USA) or a defined xeno-free culture medium, RegES (Regea 06/015, Regea 07/046, and Regea 08/013).40,41 Human foreskin fibroblast (hFFs) feeder cells (CRL-2429, ATCC) cultured in Iscove's Modified Dulbecco's Medium (IMDM, Invitrogen Corp.) with L-glutamine and $25 \mathrm{mM}$ HEPES (Invitrogen Corp.) supplemented with 10\% FBS (Invitrogen Corp.) and 1\% penicillinstreptomycin (Cambrex Bio Science Corp.,) were used for hESC culture. Confluent monolayers of hFFs were mitotically inactivated by irradiation (40 Gy) and plated at a density of $3.8 \times 10^{4}$ cells $/ \mathrm{cm}^{2}$. The growth of hESCs was monitored microscopically and culture media were changed six times per week. The hESCs were mechanically passaged every 6 to 7 days to new mitotically inactivated feeder cells. Tested lipids and lipid derivatives were all from Sigma except oleic acid and arachidonic acid, which were obtained from Cayman Chemicals. Lipids were first dissolved in absolute ethanol and stored at $-20^{\circ} \mathrm{C}$. The stock lipid solutions were further diluted in $50 \mathrm{mg} / \mathrm{mL}$ human serum albumin as a carrier protein before addition to the medium. Human ESC colonies cultured in the presence of different lipids were classified into undifferentiated, partially differentiated and differentiated categories. Undifferentiated colonies did not contain any differentiated areas and the whole colony was used for further passaging. Partially differentiated colonies contained area(s) of differentiated cells that were excluded from further passaging. Differentiated colonies did not contain any areas of undifferentiated cells and differentiated colonies were completely excluded from further passaging. IGF-II was purchased from R\&D Systems and IGF-I and heregulin- $\beta 1$ were purchased from Peprotech (Peprotech Inc., Rocky Hill, NJ, USA).

Comparison of hypoxic and normoxic conditions: hESCs were cultured in hypoxic $\left(5 \% \mathrm{O}_{2}\right)$ and normoxic $\left(21 \% \mathrm{O}_{2}\right)$ conditions using Cell$\mathrm{IQ}$, an automated cell culturing system (Chipman Technologies). ${ }^{44}$ Both conventional hES culture medium and serum- and xeno-free culture medium RegES were used. The hESCs were exposed to a 2-week culture period under normoxic or hypoxic conditions before analysis. Cells were manipulated under normoxic conditions and $\mathrm{O}_{2}$ exposure of hESCs cultured under hypoxic conditions was kept to a minimum.

\section{Cell proliferation assay}

Cell proliferation of the hESC lines was determined using a colorimetric immunoassay (Roche Diagnostics, Basel, Switzerland) based on the measurement of bromodeoxyuridine (BrdU) incorporation during DNA synthesis. The assay was performed according to the manufacturer's instructions. The hESC colonies at day 5 were labeled with BrdU-labeling solution overnight at $37^{\circ} \mathrm{C}$. The hESC colonies were dissociated with TrypleSelect (Invitrogen Corp.) and were added $\left(10^{5}\right.$ cells/well) to a 96 -well plate with 8 replicates per cell line. Cells that were not labeled with BrdU were used as a background control. The absorbance of the samples was measured at $450 \mathrm{~nm}$ using a Viktor 1429 Multilabel Counter (PerkinElmer-Wallace Inc., Norton, OH, USA).

\section{Immunocytochemistry}

Immunocytochemistry of the hESCs was performed as previously described. ${ }^{45}$ The primary antibody used was specific for Nanog (1:200, R\&D Systems, Minneapolis, MN, USA). The cells were incubated with primary antibody solution overnight at $4{ }^{\circ} \mathrm{C}$. The cells were probed with Alexa Fluor 568 (1:400, Invitrogen Corp.) secondary antibody for $1 \mathrm{~h}$ in the dark at room temperature. Human ESCs and hFFs labelled with only secondary antibody were used as negative controls. After incubation, the cells were mounted in Vectashield mounting 
medium containing 4',6-diamidino-2phenylindole (DAPI; Vector Laboratories, Burlingame, CA, USA). The labelled cells were photographed with an Olympus IX51 phase contrast microscope with fluorescence optics and Olympus DP30BW camera (Olympus Co., Tokyo, Japan).

\section{Flow cytometry}

Human ESCs were analyzed by flow cytometry using antibodies against Oct4-PE, TRA-181-FITC (both from BD Pharmingen, BD Biosciences, Franklin Lakes, NJ, USA), and SSEA-4-PE (R\&D Systems). Isolation of single cells was performed with Tryple Select (Invitrogen Corp.) and permeabilization for intracellular staining with $0,1 \%$ saponin treatment (Sigma Aldrich, St. Louis, M0, USA). Both undifferentiated and differentiated cells present in the culture dish were included in the analyses. Alexa Fluor 488 (Invitrogen Corp.) and PE-conjugated (Caltag-Medsystems Ltd, Buckingham MK18, UK) secondary antibodies were used as isotype controls. The samples were analyzed by flow cytometry (FACSAria $^{\circledR}$, BD Biosciences, Franklin Lakes, NJ, USA). The acquisition was set for 10000 events per sample. The data were analyzed using FACSDiva Software version 4.1.2 (BD Biosciences, Franklin Lakes, NJ, USA).

\section{RNA isolation and reverse transcription}

Total RNA was isolated using an RNeasy mini plus kit (Qiagen, Dusseldorf, Germany) according to the manufacturer's instructions. The concentration and quality of isolated RNA was determined using a ND-1000 Spectrophotometer (NanoDrop Technologies Inc., Wilmington, DE, USA). Complementary DNA was synthesized from $50 \mathrm{ng}$ of total RNA using a Sensiscript Reverse Transcription Kit (Qiagen) according to the manufacturer's instructions.

\section{Quantitative RT-PCR}

Both undifferentiated and differentiated hESCs in the culture plate were included in the Q-PCR analyses. Q-PCR was performed with Applied Biosystems Gene Expression Assays: GAPDH (Hs99999905_m1; 122-bp product), DNMT3B (Hs01003405_ml; 80-bp product), TDGF1 (Hs02339496_g1; 102-bp product), Nanog (Hs2387400_g1; 109-bp product), GDF3 (Hs00220998_m1; 65-bp product), GABRB3 (Hs01115771_ml; 72-bp product), and Oct4 (Hs00999632_g1; 77-bp product). GAPDH was used as a housekeeping gene control. All samples and the no-template controls were analyzed in triplicate. Q-PCR was performed with an Applied Biosystems 7300 Real-Time PCR system using the following conditions: 40 cycles of $50^{\circ} \mathrm{C}, 2 \mathrm{~min} ; 95^{\circ} \mathrm{C}, 10 \mathrm{~min}$; and $95^{\circ} \mathrm{C}$, $15 \mathrm{~s}$; followed by $60^{\circ} \mathrm{C}, 1 \mathrm{~min}$. The data were analyzed with a 7300 System SDS Software (Applied Biosystems, San Diego, CA, USA). The cycle threshold $(\mathrm{Ct})$ values were determined for every reaction. Relative quantification was calculated using the $2^{-\Delta \Delta \mathrm{Ct}}$ method. ${ }^{46}$
All data were normalized to the expression of $G A P D H$. The data are presented as mean foldchange.

\section{Quantitative RT-PCR superarray}

The molecular mechanisms activated by hypoxia were investigated by a customized PathwayFinder ${ }^{\mathrm{TM}} \mathrm{RT}^{2}$ Profiler $^{\mathrm{TM}}$ real-time PCR Array (CAPH-0616, SABiosciences, Dusseldorf, Germany) including genes from different signaling pathways (Supplementary Table 1). cDNA was synthesized from $1.0 \mu \mathrm{g}$ of total RNA using an RT ${ }^{2}$ First Strand Kit (SABiosciences, Dusseldorf, Germany) according to the manufacturer's instructions. Q-PCR was performed with an Applied Biosystems 7300 Real-Time PCR system using the following conditions: 1 cycle of $95^{\circ} \mathrm{C}, 10 \mathrm{~min} ; 40$ cycles of $95^{\circ} \mathrm{C}, 15 \mathrm{~s}$; followed by $60^{\circ} \mathrm{C}, 1 \mathrm{~min}$. The data were analyzed with 7300 System SDS Software (Applied Biosystems). The $\mathrm{Ct}$ values were determined for every reaction. Relative quantification was calculated using the $2^{-\Delta \Delta C t}$ method. ${ }^{46}$ All data were normalized to the expression of the housekeeping genes. The data are presented as mean fold-change.

\section{Statistical analyses}

The values of surface marker expression and proliferation of hESCs, expressed as mean \pm SD, were compared between the hypoxic and normoxic conditions using Student's t-test. In the proliferation analysis, comparison was made between hypoxic and normoxic condi-

Table 1 Evaluated lipids and lipid derivatives.

\begin{tabular}{|c|c|c|c|c|c|}
\hline Group & Common name/Abbr & $\begin{array}{c}\text { Carbon } \\
\text { backbone }\end{array}$ & Conc $\mu g / m L$ & $\begin{array}{l}\text { Passage } \\
\text { hES/RegES } \\
\text { medium }\end{array}$ & $\begin{array}{l}\text { Morphology* } \\
\text { hES/RegES } \\
\text { medium }\end{array}$ \\
\hline Saturated FAs & $\begin{array}{l}\text { Myristic acid } \\
\text { Stearic acid }\end{array}$ & $\begin{array}{l}14: 0 \\
18: 0\end{array}$ & $\begin{array}{l}2.5 \\
2.5\end{array}$ & $\begin{array}{l}7 / 1 \\
8 / 8\end{array}$ & $\begin{array}{l}-/- \\
-/+\end{array}$ \\
\hline Unsaturated FAs & $\begin{array}{l}\text { Palmitoleic acid, PA } \\
\text { Oleic acid, OA } \\
\text { Linoleic acid, LA } \\
\text { Conjugated linoleic acid, CLA } \\
\text { Gamma-linoleic acid, GLA } \\
\text { Alfa-linoleic acid, ALA } \\
\text { Arachidonic acid, AA } \\
\text { Eicosapentaenoic acid, EPA } \\
\text { Docosahexaenoic acid, DHA } \\
\text { Linoleic-oleic-arachidonic acid mix }\end{array}$ & $\begin{array}{l}16: 1 \\
18: 1 \\
18: 2 \\
18: 2 \\
18: 3 \\
18: 3 \\
20: 4 \\
20: 5 \\
20: 6\end{array}$ & $\begin{array}{c}2.5 \\
2.5 \\
2.5 \\
5 \\
2.5 \\
5 \\
2.5 \\
5 \\
5 \\
2.5\end{array}$ & $\begin{array}{c}11 / 15 \\
14 / 1 \\
15 / 19 \\
16 / 11 \\
13 / 3 \\
3 / 2 \\
17 / 3 \\
14 / 6 \\
3 / 3 \\
18 / 16 \\
\end{array}$ & $\begin{array}{l}+/+ \\
++/- \\
+/+ \\
++/+ \\
+/- \\
-/- \\
++/- \\
+/+ \\
-/- \\
+/+\end{array}$ \\
\hline Phospholipids & $\begin{array}{l}\text { Phosphatidylcholine, PC } \\
\text { Lysophosphatidylcholine, LPC } \\
\text { Phosphatidylethanolamine PE }\end{array}$ & $\begin{array}{l}\text { Primarily } \mathrm{C}_{18} \text { unsaturated FAs } \\
\text { Primarily } \mathrm{C}_{18} \text { unsaturated FAs }\end{array}$ & $\begin{array}{c}2.5 \\
5 \\
5\end{array}$ & $\begin{array}{l}14 / 2 \\
5 / 11 \\
3 / 10\end{array}$ & $\begin{array}{l}+/- \\
-/+ \\
-/+\end{array}$ \\
\hline Sphingolipid & Sphingosine-1-phosphate, S1P & $\mathrm{C}_{18} \mathrm{H}_{38} \mathrm{NO}_{5} \mathrm{P}$ & $10 \mu \mathrm{M}$ & $2 / 1$ & $-1-$ \\
\hline Eicosanoids & $\begin{array}{l}\text { Prostaglandin } \mathrm{E}_{2}, \mathrm{PGE}_{2} \\
\text { Prostaglandin } \mathrm{F}_{2}, \mathrm{PGF}_{2}\end{array}$ & $\begin{array}{r}\mathrm{C}_{20} \mathrm{H}_{32} \mathrm{O}_{5} \\
\mathrm{C}_{22} \mathrm{H}_{3} 3 \mathrm{NO}_{5}\end{array}$ & $\begin{array}{l}0,050 \\
0,050\end{array}$ & $\begin{array}{c}14 / 2 \\
3 / 8\end{array}$ & $\begin{array}{l}-/- \\
-/+\end{array}$ \\
\hline Sterol & Cholesterol & $\mathrm{C}_{27} \mathrm{H}_{46} \mathrm{O}$ & 2 & $16 / 5$ & $+/-$ \\
\hline Vitamin A & Retinol & $\mathrm{C}_{20} \mathrm{H}_{30} \mathrm{O}$ & 2.5 & $15 / 19$ & $++/++$ \\
\hline Catecholamine & DL-isoproterenol & $\mathrm{C}_{11} \mathrm{H}_{18} \mathrm{CINO}_{3}$ & 100 & $8 / 10$ & $-1+$ \\
\hline
\end{tabular}

${ }^{*}$ General morphology, size, and thickness of the hESC colonies were evaluated. Poor morphology: uneven edges in the colonies, thin and/or small colonies. + Satisfying morphology: some uneven edges in the colonies, colonies have medium thickness and size. ++Excellent morphology: even, thick, and big colonies. 
tions for all cell lines, cell lines cultured only in the hES medium and cell lines cultured only in the RegES medium. $\mathrm{P}$ values less than 0.05 were considered significant. The data were analyzed using SPSS 14.0 statistical software.

\section{Results}

\section{Effect of basal media, glucose concentration, and osmolarity on the growth and characteristics of hESCs}

We previously developed a defined xeno-free culture medium (RegES) based on amino acids, vitamins, antioxidants, trace minerals, and growth factors. ${ }^{40,41}$ During the development of the basic formulation, different basal media, glucose concentrations, and osmolarities were evaluated. Of the different basal media, K0-DMEM had the best performance with the xeno-free medium formulation. DMEM/F12 and DMEM containing a low D-glucose concentration $(1 \mathrm{~g} / \mathrm{L})$ resulted in excess hESC differentiation, while only minor differences in the hESC colony morphology were observed with KO-DMEM and DMEM containing a high D-glucose concentration $(4.5 \mathrm{~g} / \mathrm{L})$ (Figure 1A-D). In the presence of DMEM/F12 and both DMEM formulations, the hFF feeder cells exhibited an altered spherical morphology, whereas in KO-DMEM the feeder cells exhibited a normal elongated morphology. These results indicated that a high D-glucose concentration was more suitable for hESC culture. In addition, the osmolarity of KO-DMEM is reduced to better mimic the natural environ- ment of embryonic tissue. To further improve the performance of the xeno-free formulation, various osmolarities were evaluated in the hESC culture for 5 passages and the best performance was obtained with an osmolarity of $320 \mathrm{mOsm}$ (Figure 1E-H). An osmolarity of 260 m0sm induced the formation of small uneven colonies and although the morphology of the colonies was improved at an osmolarity of 290 m0sm, the colony size was small. An osmolarity of $350 \mathrm{~m} 0 \mathrm{sm}$ resulted in poor morphology and restricted growth of the colonies.

\section{Specific lipids and lipid derivatives enhance undifferentiated hESC growth}

As AlbuMAX (Invitrogen Corp.) contains lipid-rich BSA, we examined whether the addition of lipids could further enhance the performance of the xeno-free formulation. We evaluated various lipids and lipid derivatives in the xeno-free RegES formulation and in the conventional hES culture medium containing K0-SR. General morphology, as well as the size and thickness of the undifferentiated colonies were evaluated before each passage based on visual inspection (Table 1). The results indicated that conjugated linoleic acid, eicosapentaenoic acid, palmitoleic acid, linoleic acid, linoleic-oleic-arachidonic acid mix, and especially retinol resulted in excellent morphology of the undifferentiated colonies meaning even, thick, and big colony characteristics in both hES and RegES culture media (Table 1, Figure 2A). Myristic acid, alfalinoleic acid, docosahexaenoic acid, S1P, and PGE2 resulted in poor morphology meaning uneven edges in the colonies and thin and/or small colonies as well as induced rapid differentiation in both culture media.

In addition to evaluating the morphology of the undifferentiated colonies, we classified the hESC colonies into three categories; undifferentiated, partially differentiated, and differentiated. The number of each colony type was calculated before each passage, and a percentage value for each colony type of the total amount of colonies was calculated (Figure 2B,C). In RegES culture medium, the number of undifferentiated colonies increased and the number of differentiated colonies decreased in the presence of conjugated linoleic acid, eicosapentaenoic acid, and stearic acid when compared to the colonies cultured in the control hES medium (Figure 2C). In addition, the number of undifferentiated colonies increased in the presence of retinol, a linoleic-oleicarachidonic acid mix, DL-isoproterenol, palmitoleic acid, and linoleic acid when compared to the colonies cultured in the Albumax-RegES medium (Figure 2C). In the presence of PGF2, lysophosphatidic acid, and phosphatidylethanolamine in RegES culture medium, the number of undifferentiated colonies decreased or no improvement was detected when compared to Albumax-RegES medium (Figure 2C). In hES culture medium, the number of undifferentiated colonies increased and the number of differentiated colonies decreased in the presence of cholesterol, arachidonic acid, conjugated linoleic acid, retinol, and phosphatidylcholine when compared to the colonies cultured in the control hES medium (Figure 2B). In the presence of the linoleic-oleic-arachidonic acid mix, PGE2, DL-isoproterenol, gammalinoleic acid, stearic acid, and myristic acid, the number of undifferentiated colonies
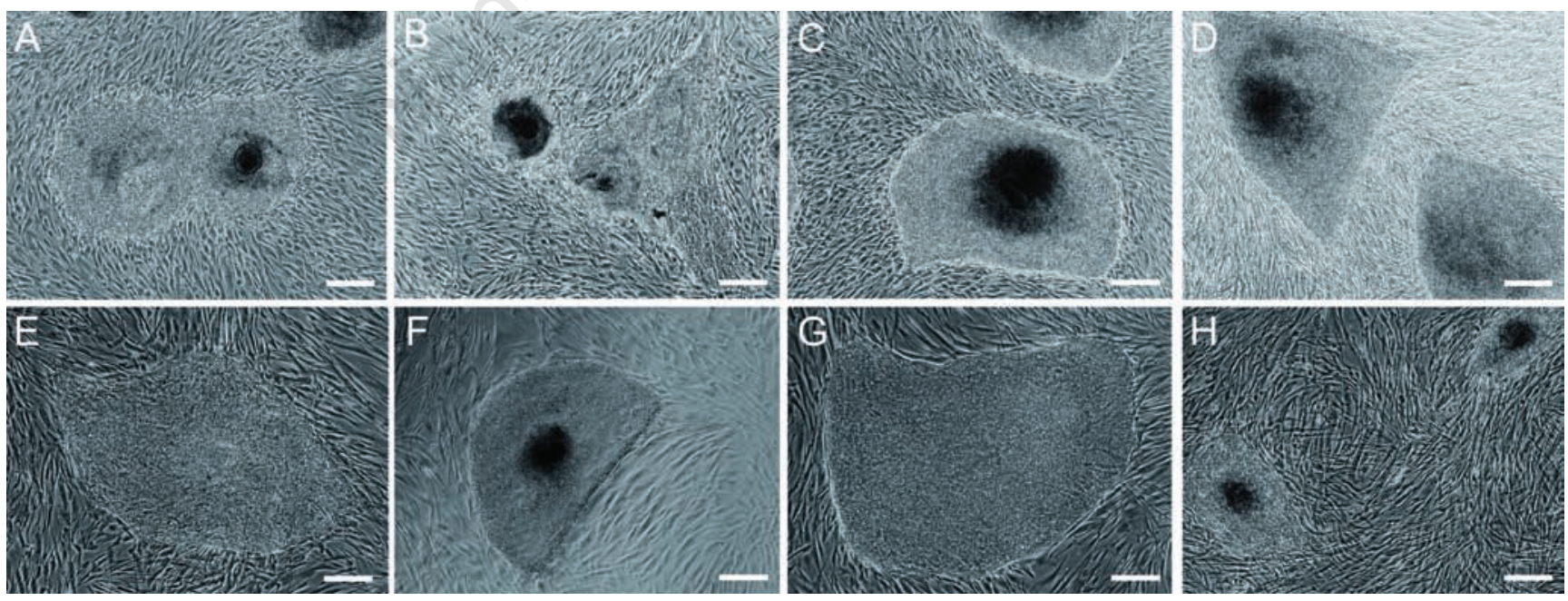

Figure 1. Effect of basal media, glucose concentration, and osmolarity on hESCs. Representative figures of hESCs (HS401) cultured in RegES supplemented with different basal media for 5 passages: DMEM/F12 (A), DMEM low D-glucose (B), DMEM high D-glucose (C), and KO-DMEM (D). Note the spherical morphology of the fibroblast feeder cells in the presence of DMEM/F12 and in both DMEM formulations. Representative figure of hESCs (HS401) cultured in RegES supplement and KO-DMEM basal medium in different osmolarities for 5 passages: $260 \mathrm{mOsm}(\mathrm{E}), 290 \mathrm{mOsm}$ (F), $320 \mathrm{mOsm}$ (G), and $350 \mathrm{mOsm}(\mathrm{H})$. Scale bar: $500 \mu \mathrm{m}$. 
decreased (Figure 2B).

Altogether, retinol, conjugated linoleic acid, and eicosapentaenoic acid resulted in satisfying or excellent colony morphology and decreased the number of differentiated colonies in both culture media.

\section{Retinol increases the proliferation} and expression of stem cell markers

Retinol was further evaluated for its effects on the maintenance of undifferentiated hESCs. Initial studies showed that 0.1 to $0.5 \mu \mathrm{M}$ retinol had no effect on self-renewal of hESCs (data not shown). Further evaluation, however, indicated that $\geq 2.0 \mu \mathrm{M}$ retinol enhanced the proliferation of hESCs and induced the expression of hESCspecific markers (Figure 3). In the presence of $2.0 \mu \mathrm{M}$ retinol, the colonies began growing earlier and already at day 3 the size of the colonies was noticeably larger as compared to the condition containing no retinol (Figure 3A). Furthermore, retinol seemed to increase the expression of pluripotency-supporting genes, especially Nanog, which had a greater than 20 -fold relative expression level in the presence of $2.0 \mu \mathrm{M}$ and $3.5 \mu \mathrm{M}$ retinol (Figure 3E). To investigate whether the mRNA of the Nanog gene results in the protein synthesis, immunocytochemical analysis was performed on hESCs cultured without and in the presence of $2.0 \mu \mathrm{M}$ retinol. The analysis indicated increased expression of Nanog in the presence of retinol (Figure 3B). Flow cytometry analysis was used to confirm the increase of stem cell marker expression in the presence of retinol (Figure 3C).

\section{Insulin induces stem cell marker}

\section{expression and is an important}

component of the xeno-free medi-

\section{um formulation}

We then tested whether insulin is an important component of the xeno-free medium formulation. We evaluated both IGF-I and IGF-II as well as a combination described by Wang and co-workers containing $10 \mathrm{ng} / \mathrm{mL}$ Activin A, $200 \mathrm{ng} / \mathrm{mL}$ IGF-I, and $10 \mathrm{ng} / \mathrm{mL}$ heregulin-1 $\beta$ for the ability to maintain the self-renewal of hESCs without insulin. ${ }^{19}$ We detected cells with an altered morphology having thin and less compact morphology and less clearly defined borders, as well as increased differentiation of hESCs cultured without insulin and in the presence of IGF-I, IGF-II, and the combination of $10 \mathrm{ng} / \mathrm{mL}$ Activin A, $200 \mathrm{ng} / \mathrm{mL}$ IGF-I, and $10 \mathrm{ng} / \mathrm{mL}$ heregulin-1 $\beta$ (Figure $4 \mathrm{~A}$ ). The cultures could not be maintained beyond 5 passages due to difficulties in the mechanical passaging of the thin and fragile colonies. When a combination of Activin A, IGF-I, and heregulin$1 \beta$ was evaluated in the RegES formulation containing insulin, the colonies exhibited better morphology and proliferation, but were thinner compared to colonies cultured in the
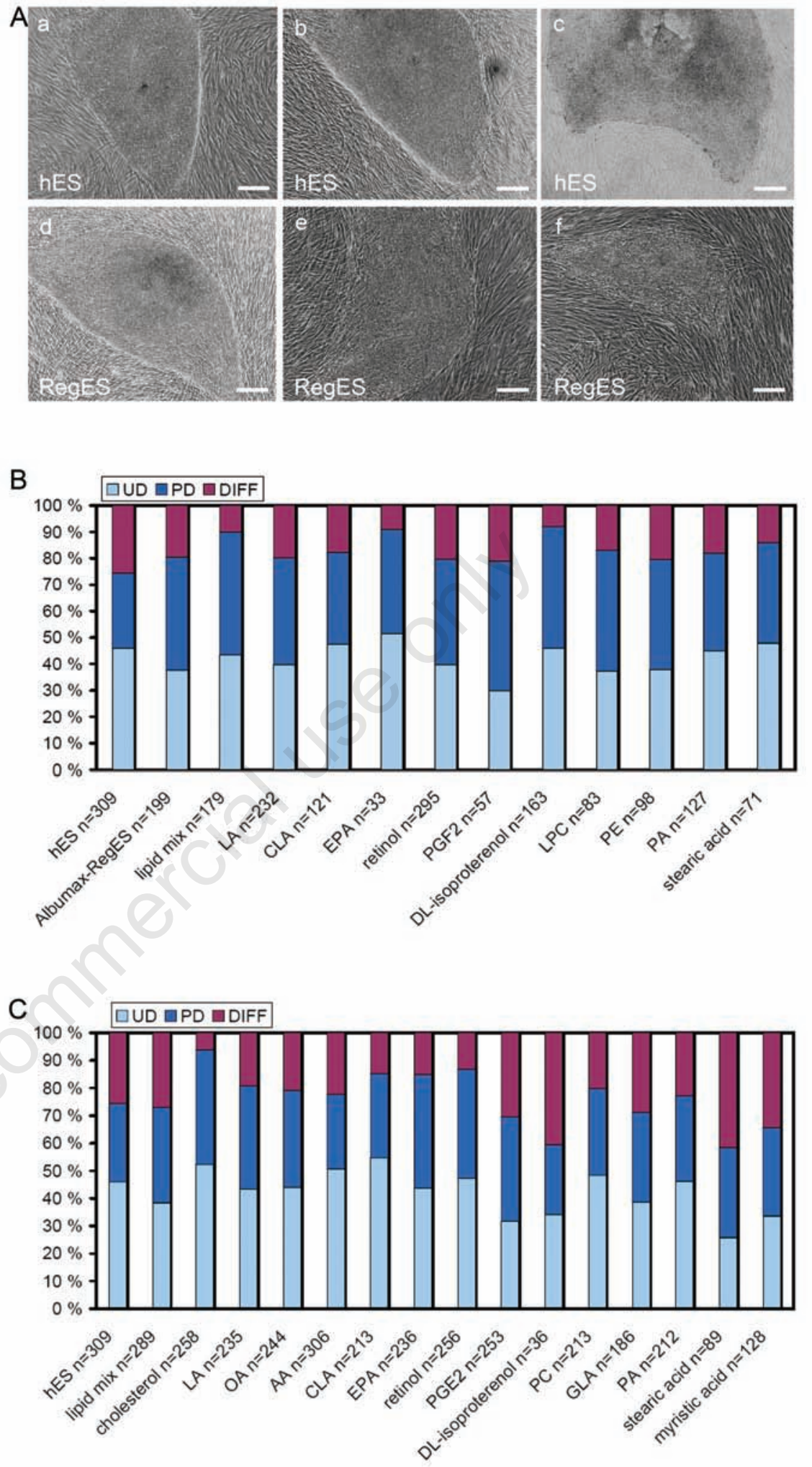

Figure 2. The morphology and differentiation stage of hESCs cultured in the presence of lipids and lipid derivatives. A) Representative figures of hESCs (HS401) cultured in the presence of retinol (a), arachidonic acid (b), PGE2 (c), conjugated linoleic acid (d), DLisoproterenol (e), and S1P (f). Scale bar: $500 \mu \mathrm{m}$. B) Ratios of undifferentiated (UD), partially differentiated (PD), and differentiated (DIFF) hESC colonies (HS401) cultured in hES medium supplemented with different lipids and lipid derivatives. C) Ratios of undifferentiated (UD), partially differentiated (PD), and differentiated (DIFF) hESC colonies (HS401) cultured in RegES medium supplemented with different lipids and lipid derivatives. 
RegES formulation containing only insulin (Figure 4A). Q-PCR and flow cytometry analysis of hESCs cultured with or without insulin indicated that insulin increased the expression of pluripotency-supporting genes as well as stem cell markers (Figure 4B and C). Our results indicate that insulin cannot be replaced with IGF-I, IGF-II, or with the combination of Activin A, IGF-I, and heregulin-1 $\beta$.

\section{Hypoxia increases proliferation and prevents spontaneous differentia- tion of hESCs}

Under hypoxic conditions, only minor spontaneous differentiation was detected within hESC colonies whereas under normoxic conditions, spontaneous differentiation of hESCs began within 5 days after passaging (Figure
$5 \mathrm{~A})$. In addition, the colonies began to form earlier and the size of the colonies was larger under hypoxic conditions. Cell proliferation assay demonstrated increased proliferation of hESCs under hypoxic conditions (Figure 5B). Significant differences in the proliferation rates under hypoxia were observed in hESCs maintained in the conventional hES culture medium $(\mathrm{P}=0.001)$, in the RegES culture medium $(\mathrm{P}<0.001)$, and in both culture media $(\mathrm{P}<0.001$; Figure 5B).

\section{Hypoxia induces the expression of stem cell markers and alters the gene expression of several signaling pathways}

To investigate the effect of oxygen tension on the translational expression of stem cell markers, flow cytometry analysis was performed on hESCs cultured under normoxic and hypoxic conditions. After culturing hESCs under these conditions for 6 days, no differences were detected in the stem cell marker expression (Oct4, SSEA-4) of hESCs cultured in the hES culture medium and only minor differences were detected in hESCs cultured in the RegES culture medium (Figure 6A). After culturing hESCs under normoxic or hypoxic conditions for 8 days, however, the expression of stem cell markers (Oct4, SSEA-4, TRA-1-81) differed between these conditions (Figure 6B). Statistical analysis of stem cell marker expression revealed a significant increase in the expression of 0ct4 in hypoxia $(\mathrm{p}<0.05$; Figure 6C). The gene expression profiles of stem cell markers (Oct4, Nanog, TDGF1, DNMTB3, $G A B R B 3$, and GDF3) were not significantly dif-

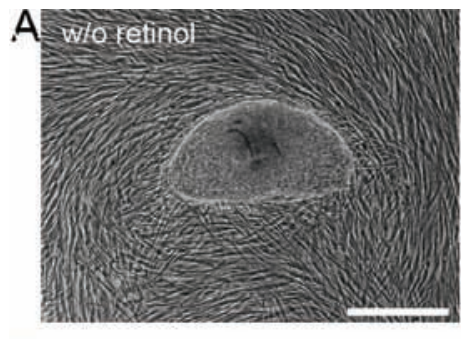

C
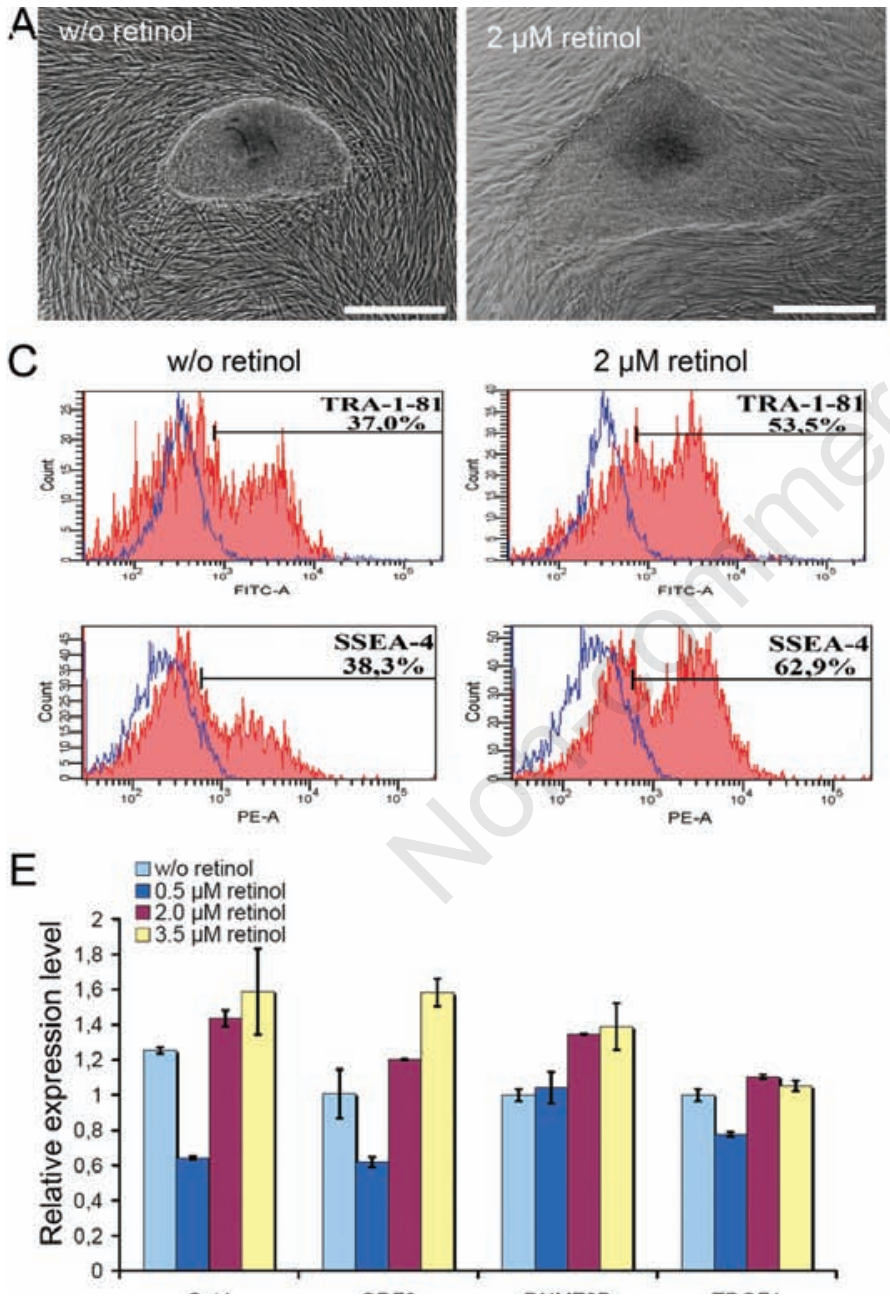
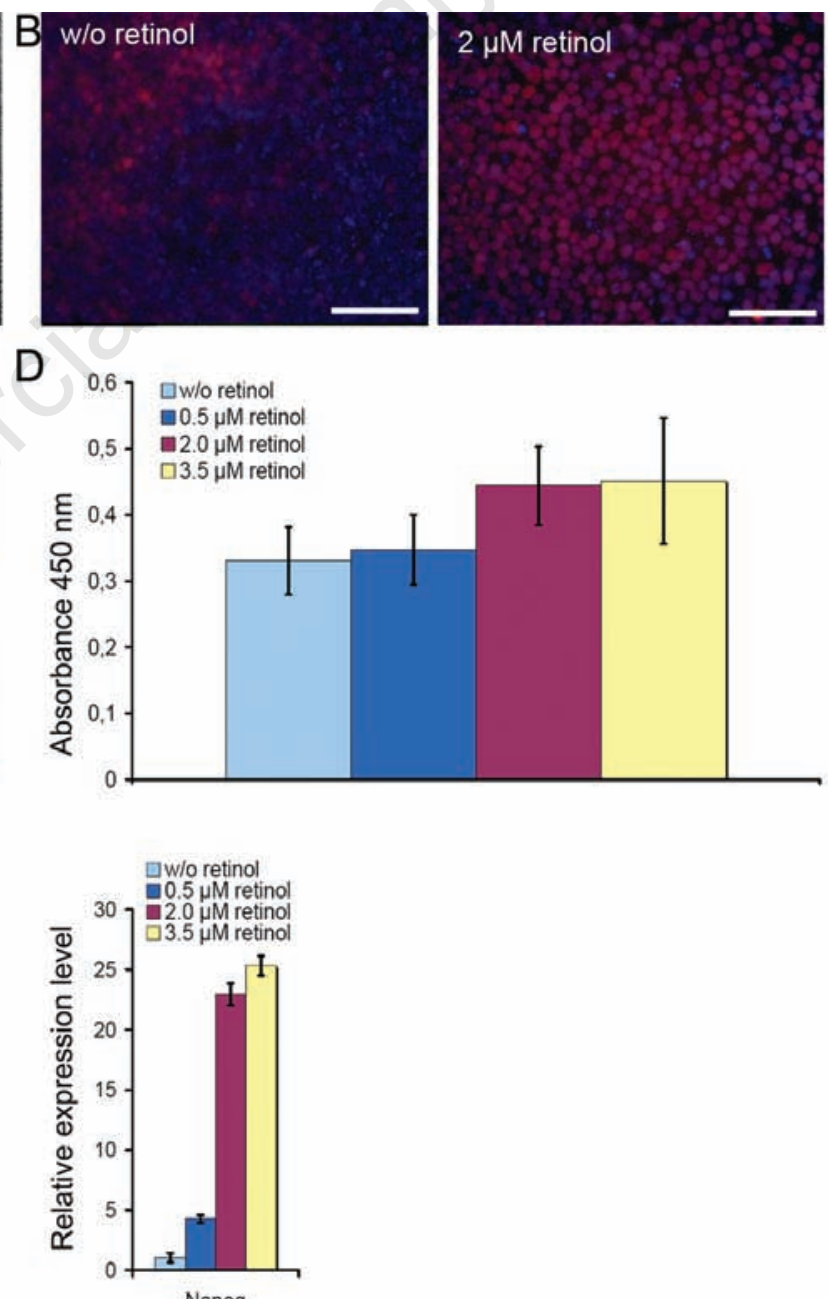

Figure 3. Retinol increases the proliferation and expression of stem cell markers. (A) Bright-field microscopy images of hESCs (Regea 07/046) at day 3 of culture without or with $2.0 \mu \mathrm{M}$ retinol for 5 passages. Colony size was larger in the presence of retinol compared to colonies cultured without retinol. Scale bar: $500 \mu \mathrm{m}$. (B) Fluorescence microscopy images of hESCs (Regea 07/046) cultured without and with $2.0 \mu \mathrm{M}$ retinol for 12 passages showing the expression of Nanog (red) and DAPI (blue). Scale bar: $200 \mu \mathrm{m}$. (C) Quantitative FACS analyses indicating expression of SSEA-4 and TRA-1-81 of hESC line Regea 07/046 on day 8 cultured without and in the presence of $0.5,2.0$ and $3.5 \mu \mathrm{M}$ retinol for 10 passages. (D) Cell proliferation analysis of $\mathrm{hESC}$ line Regea 07/046 cultured without or with 0.5 , 2.0, or $3.5 \mu \mathrm{M}$ retinol for 10 passages. (E) Quantitative RT-PCR analysis of Oct4, GDF3, DNMT3B, TDGF1, and Nanog expression in hESC line Regea 07/046 cultured without or with $0.5,2.0$, or $3.5 \mu \mathrm{M}$ retinol for 10 passages. 
ferent between hESCs cultured under hypoxic and normoxic conditions (Figure 6D). To further investigate the possible molecular mechanisms activated by hypoxia, a customized PathwayFinder ${ }^{\mathrm{TM}}$ RT $^{2}{ }^{2}$ Profiler $^{\mathrm{TM}}$ real-time PCR Array (SABiosciences) including genes from different signaling pathways was performed (Supplementary Table 1). Eight genes were upregulated and 3 genes were downregulated in hESCs cultured under hypoxic conditions in both culture media (Figure 6E, Supplementary Table 2). In addition, 8 genes were upregulated in hESCs cultured under hypoxic conditions in the hES culture medium and 2 genes were upregulated and 21 genes were downregulated in hESCs cultured in the RegES culture medium (Supplementary Table 2). The calcium and protein kinase $\mathrm{C}$ pathway, and several hypoxia signaling-related genes were altered under hypoxic conditions. Interestingly, the retinoic acid pathway seemed to be downregulated under hypoxia in hESCs cultured in the RegES culture medium.

\section{Discussion}

Many physiochemical culture conditions, including osmolarity, $\mathrm{pH}$, and glucose concentration, affect the vitality of stem cell cultures. Our results indicate that hESC characteristics are enhanced under high D-glucose concentration and an osmolarity of $320 \mathrm{m0sm}$ in defined, xeno-free culture conditions. Glucose is not just an energy source, but it also produces a wide variety of cellular signals. In fact, early embryo development in vitro is enhanced in a medium lacking glucose. ${ }^{47}$ High glucose levels in the culture medium lead to increased proliferation of mESCs through the induction of peroxisome proliferator-activated receptor $\delta$ (PPARס), which is mediated, at least in part, through the induction of cyclooxygenase-2 expression and PGE2. ${ }^{48}$ Our results indicate that glucose is important for hESC, but the possible mechanism of glucose on the selfrenewal of hESCs requires further investigation. Ludwig and co-workers previously demonstrated that the optimal osmolarity for feeder cell-free hESC culture under defined conditions is $350 \mathrm{m0sm} .{ }^{38}$ In the present study, however, an osmolarity of $350 \mathrm{~m} 0 \mathrm{sm}$ resulted in poor morphology of hESCs on feeder cells. This difference may have been due to differences in the medium formulation or in the culture matrix and/or feeder cells.

Little is known about the effects of lipidmediated signaling on the undifferentiated growth of hESCs. Garcia-Gonzalo and co-work-
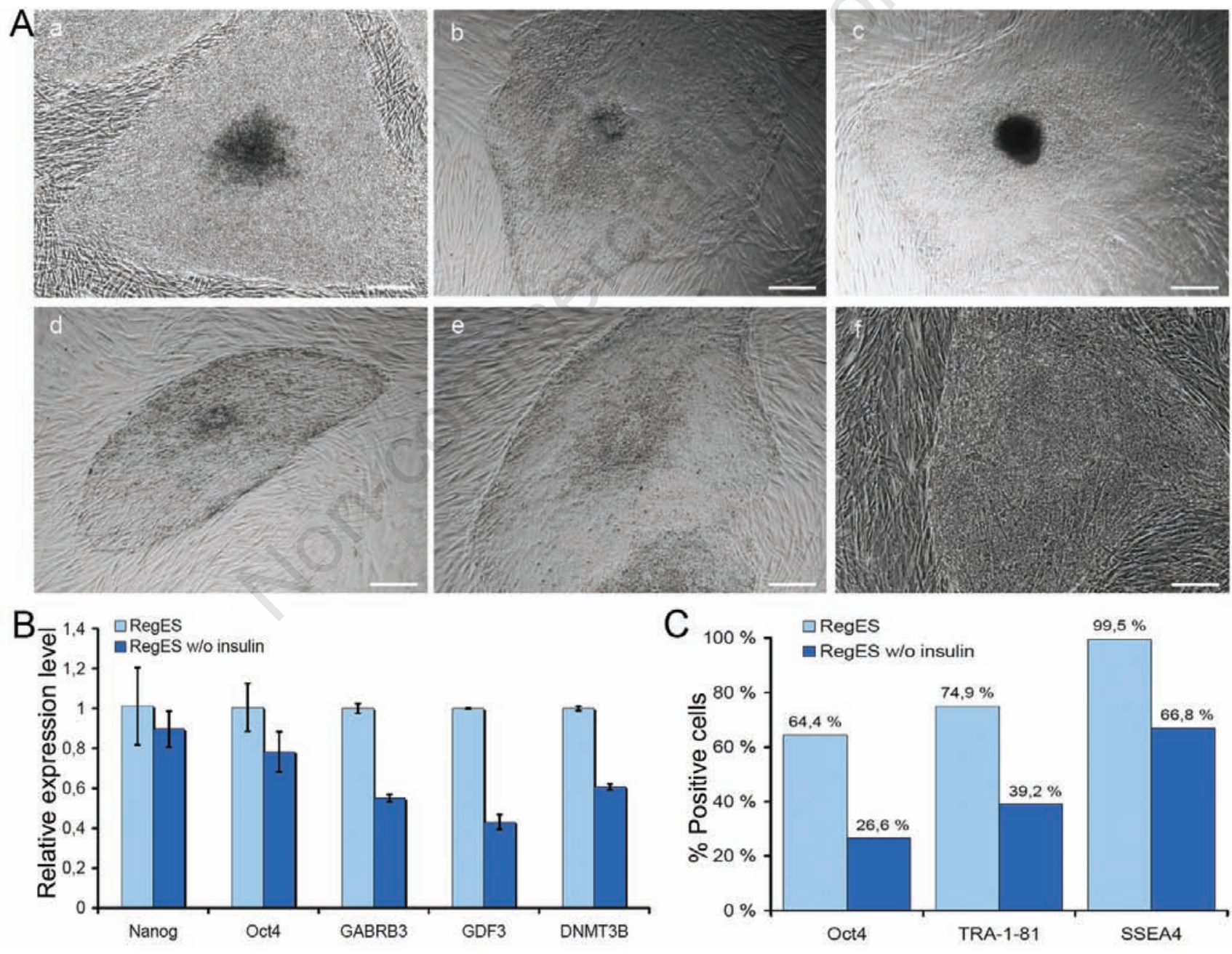

Figure 4. Insulin is an important component of the xeno-free culture medium RegES. (A) Representative figures of the hESC line Regea 07/046 cultured in RegES medium under the indicated conditions for 5 passages: control RegES (a), RegES without insulin (b), RegES without insulin, plus $10 \mathrm{ng} / \mathrm{mL}$ Activin A, $200 \mathrm{ng} / \mathrm{mL}$ IGF-I, and $10 \mathrm{ng} / \mathrm{ml}$ heregulin-1 $\beta$ (c), RegES without insulin, plus IGF-I (d), RegES without insulin, plus IGF-II (e), RegES plus $10 \mathrm{ng} / \mathrm{mL}$ Activin A, $200 \mathrm{ng} / \mathrm{mL}$ IGF-I, and $10 \mathrm{ng} / \mathrm{mL}$ heregulin-1 $\beta$ (f). Scale bar: $500 \mu \mathrm{m}$. (B) Quantitative RT-PCR analysis of Nanog, Oct4, GABRB3, GDF3, and DNMT3B expression in hESC line Regea $07 / 046$ cultured without or with insulin for 10 passages. (C) Quantitative FACS analyses indicating expression of Oct4, TRA-1-81, and SSEA-4 of hESC line 07/046 cultured without or with insulin for 10 passages. 
ers demonstrated that the albumin-associated lipids present in KO-SR have a strong positive effect on hESC self-renewal. ${ }^{26}$ We also noticed a superior effect of AlbuMAX (Invitrogen Corp.) on hESC self-renewal and in the present study we evaluated many different lipids and lipid derivatives in the culture of hESCs. Retinol, conjugated linoleic acid, and eicosapentaenoic acid improved hESC colony mor- phology and decreased the number of differentiated colonies in both culture media tested and are therefore potential supplements for culture media formulations. The optimal performance of AlbuMAX (Invitrogen Corp.) may be due to a synergism between the different lipids, and therefore lipids with positive effects on hESC self-renewal should be further evaluated to determine optimal combinations and

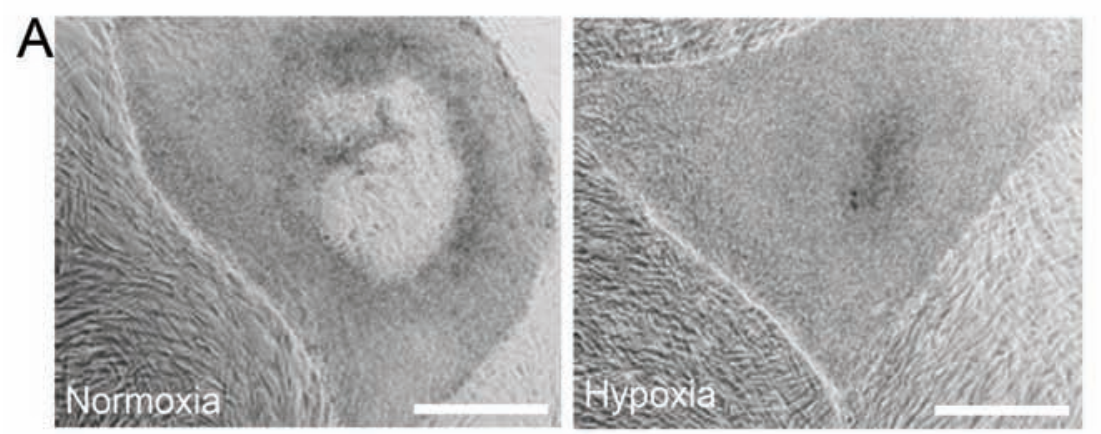

B
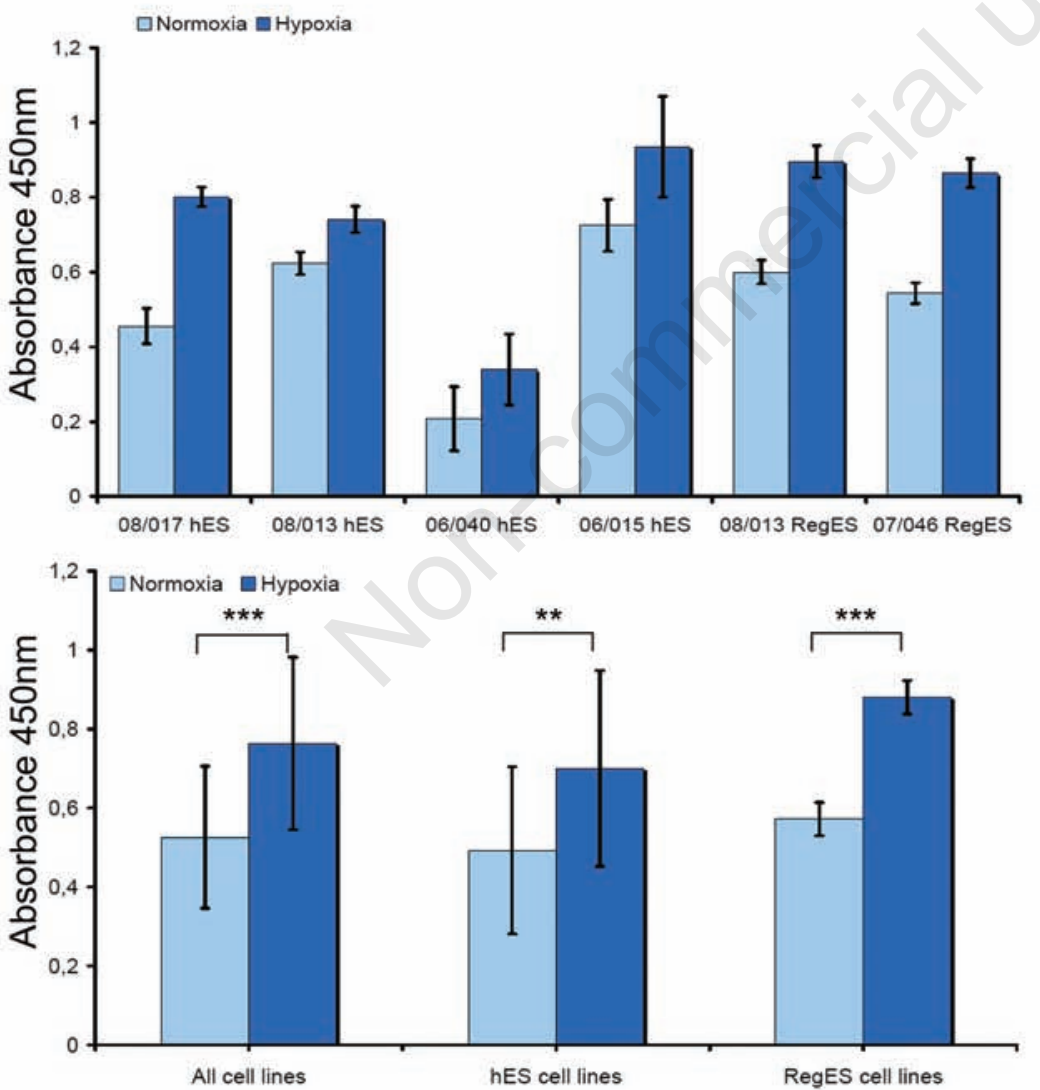

Figure 5. Hypoxia prevents spontaneous differentiation and increases proliferation of hESCs. (A) Representative figure of hESC line Regea 07/046 cultured in RegES medium under normoxic and hypoxic conditions at day 7 . Hypoxia improved the cell colony morphology and prevented spontaneous differentiation. Scale bar: $500 \mu \mathrm{m}$. (B) Cell proliferation analysis of hESCs cultured in hES and RegES media under normoxic and hypoxic conditions. Hypoxia increased the proliferation rate of hESCs. The data in the diagram are presented as mean \pm SD. ${ }^{* *} \mathbf{P}=\mathbf{0 . 0 0 1}$ and ${ }^{* * *} \mathrm{P}<0.001$. concentrations. Consistent with the previous data, ${ }^{23,26}$ S1P alone without PDGF supplementation neither enhanced proliferation nor prevented apoptosis, as described previously. ${ }^{25} 0 \mathrm{n}$ the contrary, S1P caused excessive cell death in both culture media. Consistent with the data obtained with $\mathrm{mESCs},{ }^{29,30}$ retinol seems to increase the proliferation of hESCs and induce the expression of stem cell markers, especially Nanog, although our data indicates that an increased concentration of retinol is required, compared to what was originally shown in Chen et al 2007. In comparison to published data with $\mathrm{mESCs},{ }^{30}$ our results indicate that retinol could mediate the self-renewal of hESCs via the overexpression of Nanog. In addition, insulin was an important component of the xeno-free RegES formulation. Although Wang and co-workers suggested that insulininduced insulin receptor and insulin-like growth factor 1 receptor signaling as well as low levels of bFGF are not sufficient to maintain hESC self-renewal, ${ }^{19}$ our results indicate that insulin is essential for the self-renewal of hESCs and cannot be replaced with IGF-I, IGFII, or a combination of Activin A, IGF-I, and heregulin-1 $\beta$, at least when the hESCs are cultured on feeder cells.

Previous reports of the effects of hypoxic conditions on hESCs are controversial in terms of proliferation and prevention of spontaneous differentiation. Although the hypoxia system utilized in the present study was not optimal due to the need to manipulate the cells under normoxic conditions, we found that exposure to hypoxia prevented spontaneous differentiation, significantly increased proliferation, and supported hESC self-renewal. The transcriptional expression of common genes associated with pluripotency was not affected by hypoxia, which is consistent with previous reports..$^{37,49}$ At the translational level, the expression of Oct4 increased significantly under hypoxic conditions, indicating a possible mechanism for hypoxia induced self-renewal and prevention of spontaneous differentiation. The investigation of transcriptional expression of genes relating to different signaling pathways showed activation of the calcium and protein kinase $\mathrm{C}$ pathway, the cell survival pathway and several hypoxia signaling-related genes under hypoxic conditions. The retinoic acid pathway generally associated with the differentiation ${ }^{50}$ was downregulated in hypoxia in hESCs cultured only in the RegES culture medium, but these results must be verified at the translational level. The transcriptional expression of hypoxia-inducible factors HIF$1 \alpha$, HIF-2 $\alpha$, and HIF-3 $\alpha$ was not affected by hypoxia which is consistent with previous reports. ${ }^{37,49,51}$ However it has been shown that under hypoxic conditions HIFs expression is increased at protein level indicating that HIFs may be largely regulated at translational level. ${ }^{51}$ 

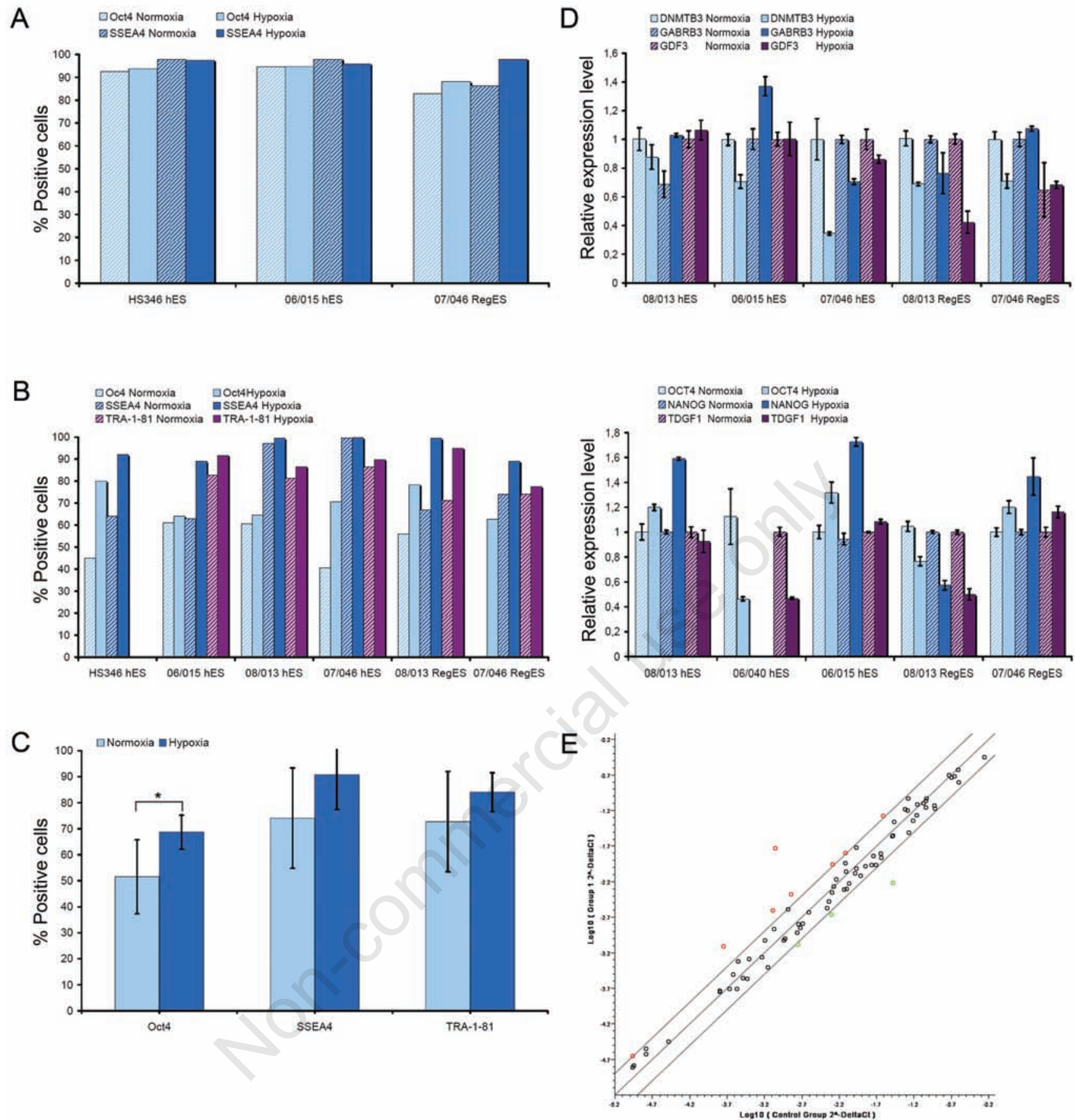

Figure 6. Hypoxia induces translational expression of stem cell markers. (A) FACS analysis of hESCs cultured under normoxic and hypoxic conditions at day 6. B) FACS analysis of hESCs cultured under normoxic and hypoxic conditions at day 8. C) Oct4 expression levels differed significantly under hypoxic conditions. $\left.{ }^{*} \mathrm{p}<0.05 \mathrm{D}\right)$ Quantitative RT-PCR analysis of Nanog, Oct4, GABRB3, GDF3, DNMT3B, and TDGF1 expression in hESCs cultured under normoxic and hypoxic conditions. E) Quantitative RT-PCR signaling pathway superarray analysis of hESCs cultured under hypoxic conditions showing upregulation of 8 genes and downregulation of 3 genes.

They also suggested that HIF-3 $\alpha$ regulates the expression of both HIF-1 $\alpha$ and HIF- $2 \alpha$, and suggested that HIF- $2 \alpha$ regulates hESC pluripotency and proliferation under hypoxic conditions. Similar to our results, they reported increased proliferation, prevention of spontaneous differentiation, and upregulation of 0ct4 protein under hypoxia. ${ }^{51}$ In contrast to our results and other previously published results,,$^{37,49}$ however, they reported increased transcriptional expression of the stem cell markers Nanog, Oct4, and Sox $2{ }^{51}$ The use of defined, xeno-free culture conditions may facilitate the identification and understanding of the mechanisms governing the self-renewal and differentiation of stem cells as well as enable the provision of high quality cells for the future needs.

\section{References}

1. Thomson J, Itskovitz-Eldor J, Shapiro S et al. Embryonic stem cell lines derived from human blastocysts. Science 1998;282:1145-7.

2. Skottman H, Narkilahti S, Hovatta 0 . Challenges and approaches to the culture 
of pluripotent human embryonic stem cells. Regen Med 2007;2:265-3.

3. Koivisto $H$, Hyvärinen $M$, Strömberg A et al. Cultures of human embryonic stem cells - serum replacement medium or serum-containing media and the effect of basic fibrolast growth factor. Reproductive BioMedicine Online 2004;9:330-7.

4. Inzunza J, Gertow K, Stromberg MA et al. Derivation of human embryonic stem cell lines in serum replacement medium using postnatal human fibroblasts as feeder cells. Stem Cells 2005;23:544-9.

5. Xu C, Inokuma MS, Denham J et al. Feeder-free growth of undifferentiated human embryonic stem cells. Nat Biotechnol 2001;19:971-4.

6. McDevitt T, Palecek SP. Innovation in the culture and derivation of pluripotent human stem cells. Curr Opin Biotechnol 2008;19:527-3.

7. Vallier L, Alexander M, Pedersen RA. Activin/Nodal and FGF pathways cooperate to maintain pluripotency of human embryonic stem cells. J Cell Sci 2005;118:449509.

8. Martin MJ, Muotri A, Gage F, Varki A. Human embryonic stem cells express an immunogenic nonhuman sialic acid. Nat med 2005;11:228-32.

9. Cobo F, Stacey G, Hunt C et al. Microbiological control in stem cell banks: approaches to standardisation. Appl Microbiol Biotechnol 2005;68:456-66.

10. Skottman H, Hovatta O. Culture conditions for human embryonic stem cells. Reproduction 2006;132:691-8.

11. Beattie GM, Lopez AD, Bucay $\mathrm{N}$ et al. Activin A maintains pluripotency of human embryonic stem cells in the absence of feeder layers. Stem Cells 2005;23:489-95.

12. James D, Levine AJ, Besser D, HemmatiBrivanlou A. TGFbeta/activin/nodal signaling is necessary for the meaintenance of pluripotency in human embryonic stem cells. Development 2005;132: 1273-82.

13. Xiao L, Yuan X, Sharkis SJ. Activin A maintains self-renewal and regulates fibroblast growth factor, Wnt and bone morphogenic protein pathways in human embryonic stem cells. Stem Cells 2006;24:1476-86.

14. Xu R, Peck R, Li D et al. Basic FGF and suppression of BMP signaling sustain undifferentiated proliferation of human ES cells. Nat Methods 2005;2:185-190.

15. Sato N, Meijer L, Skaltsounis L et al. Maintenance of pluripotency in human and mouse embryonic stem cells through activation of Wnt signaling by a pharmacological GSK-3-specific inhibitor. Nat Med 2004;10:55-63.

16. Dravid G, Ye Z, Hammond $\mathrm{H}$ et al. Defining the role of Wnt/beta-catenin signaling in the survival, proliferation, and self-renew- al of human embryonic stem cells. Stem Cells 2005;23:1489-501.

17. Wang G, Zhang H, Zhao Y et al. Noggin and bFGF cooperate to maintain the pluripotency of human embryonic stem cells in the absence of feeder layers. Biochem Biophys Res Commun 2005;330:934-42.

18. Bendall SC, Stewart MH, Menendez P et al. IGF and FGF cooperatively establish the regulatory stem cell niche of pluripotent human cells in vitro. Nature 2007;448: 1015-21.

19. Wang L, Schulz TC, Sherrer ES et al. Selfrenewal of human embryonic stem cells requires insulin-like growth factor-1 receptor and ERBB2 receptor signaling. Blood 2007;110: 4111-9.

20. Watanabe K, Ueno M, Kamiya D et al. A ROCK inhibitor permits survival of dissociated human embryonic stem cells. Nat Biotechnol 2007;25:681-6.

21. Pyle AD, Lock LF, Donovan PJ. Neurotrophins mediate human embryonic stem cell survival. Nat Biotechnol 2006;24:344-50.

22. Soh BS, Song CM, Vallier L et al. Pleiotrophin enhances clonal growth and long-term expansion of human mebryonic stem cells. Stem Cells 2007;25:3029-37.

23. Pebay A, Wong RC, Pitson SM et al. Essential roles of sphingosine-1-phosphate and platelet-derived growth factor in the maintenance of human embryonic stem cells. Stem Cells 2005;23:1541-8.

24. Wong RC, Tellis I, Jamshidi P et al. Antiapoptotic effect of sphingosine-1-phosphate and platelet-derived growth factor in human embryonic stem cells. Stem Cells Dev 2007;16:989-1001.

25. Inniss K, Moore H. Mediation of apoptosis and proliferation of human embryonic stem cells by sphingosine-1-phosphate. Stem Cells Dev 2006;15:789-96.

26. Garcia-Gonzalo FR, Izpisua Belmonte JC. Albumin-associated lipids regulate human embryonic stem cell self-renewal. Plos One 2008;3:e1384.

27. Dottori M, Leung J, Turnley AM, Pébay A. Lysophosphatidic acid inhibits neuronal differentiation of neural stem/progenitor cells derived from human embryonic stem cells. Stem Cells 2008;26:1146-54.

28. Liou JY, Ellent DP, Lee $\mathrm{S}$ et al. Cyclooxygenase-2-derived prostaglandin e2 protects mouse embryonic stem cells from apoptosis. Stem Cells 2007;25:1096103.

29. Chen L, Khillan JS. Promotion of feederindependent self-renewal of embryonic stem cells by retinol (vitamin A). Stem Cells 2008;26:1858-64.

30. Chen L, Yang M, Dawes J, Khillan JS. Suppression of ES cell differentiation by retinol (vitamin A) via the overexpression of Nanog. Differentiation 2007;75:682-93.
31. Covello KL, Simon MC. HIFs, hypoxia, and vascular development. Curr Top Dev Biol 2004;62:37-54.

32. Jeong $\mathrm{CH}$, Lee HJ, Cha JH et al. Hypoxiainducible factor-1 alpha inhibits selfrenewal of mouse embryonic stem cells in Vitro via negative regulation of the leukemia inhibitory factor-STAT3 pathway. J Biol Chem 2007;282:13672-9.

33. Lee SH, Heo JS, Han HJ. Effect of hypoxia on 2-deoxyglucose uptake and cell cycle regulatory protein expression of mouse embryonic stem cells: involvement of Ca2+/PKC, MAPKs and HIF-1alpha. Cell Physiol Biochem 2007;19:269-82.

34. Peura TT, Bosman A, Stojanov T. Derivation of human embryonic stem cell lines. Theriogenology 2007;67:32-42.

35. Chen HF, Kuo HC, Chen $\mathrm{W}$ et al. A reduced oxygen tension (5\%) is not beneficial for maintaining human embryonic stem cells in the undifferentiated state with short splitting intervals. Hum Reprod 2009;24:71-80.

36. Prasad SM, Czepiel M, Cetinkaya C et al. Continuous hypoxic culturing maintains activation of Notch and allows long-term propagation of human embryonic stem cells without spontaneous differentiation. Cell Prolif 2009;42:63-74.

37. Westfall SD, Sachdev S, Das $P$ et al. Identification of oxygen-sensitive transcriptional programs in human embryonic stem cells. Stem cells dev 2008;17:869-81.

38. Ludwig TE, Levenstein ME, Jones JM et al. Derivation of human embryonic stem cells in defined conditions. Nat Biotechnol 2006;24:185-7.

39. Yoshida Y, Takahashi K, Okita K et al. Hypoxia enhances the generation of induced pluripotent stem cells. Cell Stem cell 2009;5:237-41.

40. Rajala K, Lindroos B, Hussein SM et al. A Defined and Xeno-free Culture Method Enabling the Establishment of Clinicalgrade Human Embryonic, Induced Pluripotent and Adipose Stem Cells. Plos One 2010;5:e10246.

41 Rajala K, Suuronen R, Hovatta 0 et al. Formulations and methods for culturing embryonic stem cells. Patent application 2007;601924,908.

42. Ström S, Inzunza J, Grinnemo KH et al. Mechanical isolation of the inner cell mass is effective in derivation of new human embryonic stem cell lines. Human Reproduction 2007;22:3051-8.

43. Inzunza J, Sahlen S, Holmberg $\mathrm{K}$ et al. Comparative genomic hybridization and karyotyping of human embryonic stem cells reveals the occurrence of an isodicentric X chromosome after long-term cultivation. Mol Hum Reprod 2004;10:461-6.

44. Narkilahti S, Rajala K, Pihlajamaki H et al. 


\section{Article}

Monitoring and analysis of dynamic growth of human embryonic stem cells: comparison of automated instrumentation and conventional culturing methods. Biomed Eng Online 2007;6:11.

45. Rajala K, Hakala H, Panula S et al. Testing of nine different xeno-free culture media for human embryonic stem cell cultures. Hum Reprod 2007;22:1231-8.

46. Livak KJ, Schmittgen TD. Analysis of relative gene expression data using real-time quantitative PCR and the 2(-Delta Delta C(T)) method. Methods 2001;25:402-8.
47. Conaghan J, Hardy K, Leese $\mathrm{HJ}$ et al. Culture of human preimplantation embryos to the blastocyst stage: a comparison of 3 media. Int J Dev Biol 1998;42:88593.

48. Kim YH, Han HJ. High-glucose-induced prostaglandin $\mathrm{E}(2)$ and peroxisome proliferator-activated receptor delta promote mouse embryonic stem cell proliferation. Stem cells 2008;26:745-55.

49. Forsyth NR, Kay A, Hampson K et al. Transcriptome alterations due to physiological normoxic $\left(\begin{array}{ll}2 \% & 02\end{array}\right)$ culture of human embryonic stem cells. Regen Med 2008;3:817-33.

50. Inanç B, Elçin AE, Elçin YM. Human embryonic stem cell differentiation on tissue engineering scaffolds: effects of NGF and retinoic acid induction. Tissue Eng Part A 2008;14:955-64.

51. Forristal CE, Wright KL, Hanley NA et al. Hypoxia inducible factors regulate pluripotency and proliferation in human embryonic stem cells cultured at reduced oxygen tensions. Reproduction 2010;139:85-97. 